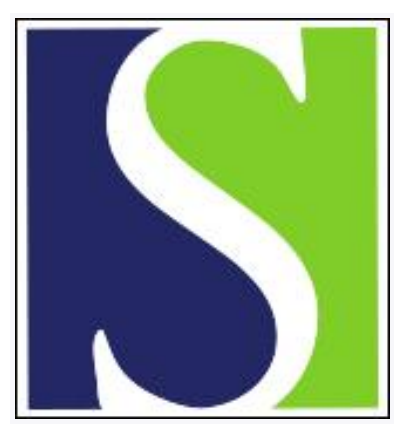

Scand J Work Environ Health 1995;21(6):440-449

https://doi.org/10.5271/sjweh.60

Issue date: Dec 1995

HARBO, a simple computer-aided observation method for recording work postures

by Wiktorin C, Mortimer M, Ekenvall L, Kilbom Å, Wigaeus Hjelm E

The following article refers to this text: 2010;36(1):3-24

Key terms: epidemiology; ergonomics; exposure assessment; postural load; reliability

This article in PubMed: www.ncbi.nlm.nih.gov/pubmed/8824750

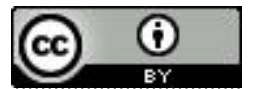




\title{
HARBO, a simple computer-aided observation method for recording work postures
}

\author{
by Christina Wiktorin, BSc, ${ }^{1,2}$ Monica Mortimer, MPT, ${ }^{3}$ Lena Ekenvall, PhD', Åsa Kilbom, PhD, ${ }^{4}$ \\ Ewa Wigaeus Hjelm, PhD
}

Wiktorin C, Mortimer M, Ekenvall L, Kilbom $\AA$, Wigaeus Hjelm E. HARBO, a simple computer-aided observation method for recording work postures. Scand J Work Environ Health 1995;21:440—9.

\begin{abstract}
Objectives The aim of the study was to present an observation method focusing on the positions of the hands relative to the body and to evaluate whether this simple observation technique gives a reliable estimate of the total time spent in each of five work postures during one workday.

Methods In the first part of the study the interobserver reliability of the observation method was tested with eight blue-collar workers. In the second part the observed time spent with work above the shoulder level was tested in relation to an upper-arm position analyzer, and observed time spent in work below knuckle level was tested in relation to a trunk flexion analyzer, both with 72 blue-collar workers.

Results The interobserver reliability for full-day registrations was high. The intraclass correlation coefficients ranged from 0.99 to 1.00 . The observed duration of work with hands above shoulder level correlated well with the measured duration of pronounced arm elevation $\left(>75^{\circ}\right.$ ). The product moment correlation coefficient was 0.97 . The observed duration of work with hands below knuckle level correlated well with the measured duration of pronounced trunk flexion angles $\left(>40^{\circ}\right.$ ). The product moment correlation coefficient was 0.98 .

Conclusion The present observation method, designed to make postural observations continuously for several hours, is easy to learn and seems reliable.
\end{abstract}

Key terms epidemiology, ergonomics, exposure assessment, postural loads, reliability.

Biomechanical studies have demonstrated that elevation (flexion and abduction) of the upper arm from the neutral position increases the mechanical load on the shoulder $(1-2)$ and that a seated position or a trunk flexed position increases the mechanical load on the lumbar spine (3).

Epidemiologic studies indicate that work with elevated arms or work above shoulder level seems to increase the risk for shoulder or neck disorders (4). Work in a flexed position or work in a sitting position increases the risk for low-back disorders (5). The exposure assessment used in epidemiologic studies on musculoskeletal disorders is usually poor $(6-9)$. There is still a lack of quantitative data, which hampers the implementation of efficient ergonomic prevention and intervention programs. Several observation methods for analyzing pos- tures and movements have been developed (10-16). However, they are time-consuming and labor intensive (17).

The aims of this study were to design an observation method assessing work postures in all types of jobs, during a whole workday, and to analyze the reliability of the method. The main characteristic of the method is that the positioning of the hands is regarded as a proxy for postural demands on the neck or shoulder and low back.

\section{Design of the observation method, HARBO}

The observation method HARBO (hands relative to the body) has been designed to cover long recording periods

1 Department of Occupational Health, NVSO, Karolinska Hospital, Stockholm, Sweden.

2 Department of Epidemiology/IMM, Karolinska Institute, Stockholm, Sweden.

3 Division of Occupational Medicine, National Institute of Occupational Health, Solna, Sweden.

4 Division of Applied Work Physiology, National Institute of Occupational Health, Solna, Sweden.

5 Division of Work and Environmental Physiology, National Institute of Occupational Health, Solna, Sweden.

Reprint requests to: Ms Christina Wiktorin, Department of Occupational Health, NVSO, Karolinska hospital, S-171 76 Stockholm, Sweden. 
(several hours), and it is used to register the duration of five standard postures. The registrations are made continuously in real time with the help of a handheld computer. The observer concentrates on the placement of the worker's hands. The following five mutually exclusive work postures or activities are observed:

1. Standing, walking with hand or hands above shoulder level (sector A, figure 1). This posture is defined to occur when the subject works with either hand above shoulder level. The shoulder level is defined by the height of the acromion.

2. Standing, walking with hands fixed between the shoulder and knuckle level (sector B, figure 1). This posture is defined to occur when the subject works with both hands between the shoulder and knuckle level. Thus both hands must be needed to accomplish the task. This position is assumed to describe more constrained (fixed) postures than when the task is accomplished with one hand or without using the hands. Knuckle level is defined by the height of the metacarpo phalangeal joints of the hands when the subject is standing upright with the arms hanging down. The hands are also considered to be fixed when the subject carries objects in one hand if the weight of the burden is over $50 \mathrm{~N}$.

3. Standing, walking with hands not fixed between the shoulder and knuckle level (figure 1). This posture is defined to occur when the subject works with tasks that do not require the use of two hands, such as making a telephone call, supervision, and the like. Carrying less than $50 \mathrm{~N}$ in one hand is also registered in this category.

4. Standing, walking with hand or hands fixed below the knuckle level (sector C, figure 1). This posture is defined to occur when the subject works with either hand below the knuckle level. This posture includes stooping, kneeling, and squatting.

5. Sitting. This posture is defined to occur when the subject sits. In the present study this posture included breaks.

The duration of each posture is registered continuously in real time with the help of a small handheld personal computer (Psion Organizer II mod XP). The software designed for another observation method, the portable ergonomic observation (PEO) method (15), was used to collect the data. For the present method, four keys on the keyboard are used, each corresponding to one of the four standing postures. When the subject performs work in one of the postures, the observer activates the corresponding key. The display on the computer indicates the active key. Registration continues until the observer either activates one of the other three keys or

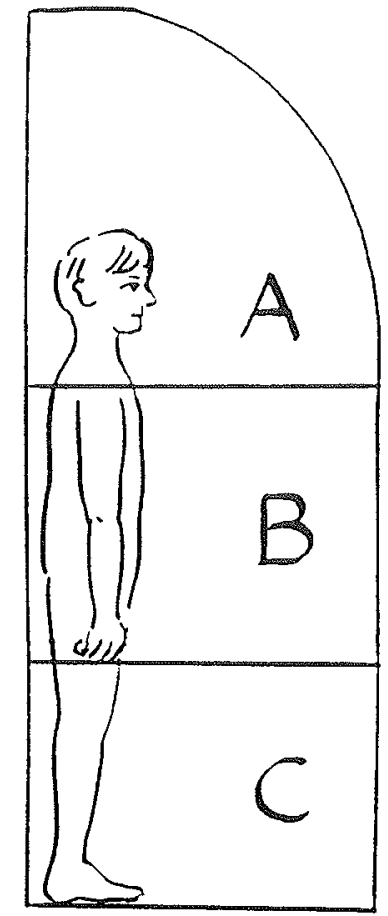

Figure 1. Three spatial sectors defining three work postures in the observation method HARBO: standing work with the hands above shoulder level (A), standing and walking with the hands between shoulder and knuckle level (B), and standing work with the hands below knuckle level $(C)$.

inactivates the active one. When a key is inactivated, the display is empty, indicating a sitting position. After the data collection, the data are transferred to and analyzed on a personal computer using the PEO software program (15). The software calculates and stores the start and stop and the total time for each event in seconds. It gives more information (eg, how many times each key is activated and the mean duration of each event registered on the keyboard), but these functions were not used in the present study.

\section{Interobserver reliability}

The intramethod reliability of the HARBO method was tested by letting two observers simultaneously collect data when observing the same workers. The purpose was to evaluate the possible influence of the observer on the observations.

\section{Subjects and methods}

The study group consisted of eight blue-collar workers, six men and two women, from five occupations. The subjects were selected from occupations with a wide range of times spent in the different standing or walking positions. Thus two ceiling builders, one carpet layer, two railway track layers, one chocolate assembly-line worker, and two car assembly-line workers were selected to represent these work postures. The mean age of the 
study group was 40 (range $25-63$ ) years, and the mean body height 173 (range 160-184) cm.

Two observers simultaneously followed each work$\mathrm{er}$, and both made registrations individually and continuously during the whole shift (lunch break excluded). They were placed apart to prevent the registrations made by one observer from being seen by the other. The eight parallel observations were made by five observers (physiotherapists) well trained in the observation method. One of the observers (MM = observer A) participated on all eight occasions. The other four observers (GP, KS, $\mathrm{EW}, \mathrm{CW}=$ observer $\mathrm{B}$ ) participated on two occasions each.

One additional full-day observation with observer A and a physiotherapist trained only $1 \mathrm{~h}$ in the observation method was made on a railway track layer, not included in the study group. We included this procedure to see if the observation method was difficult to learn.

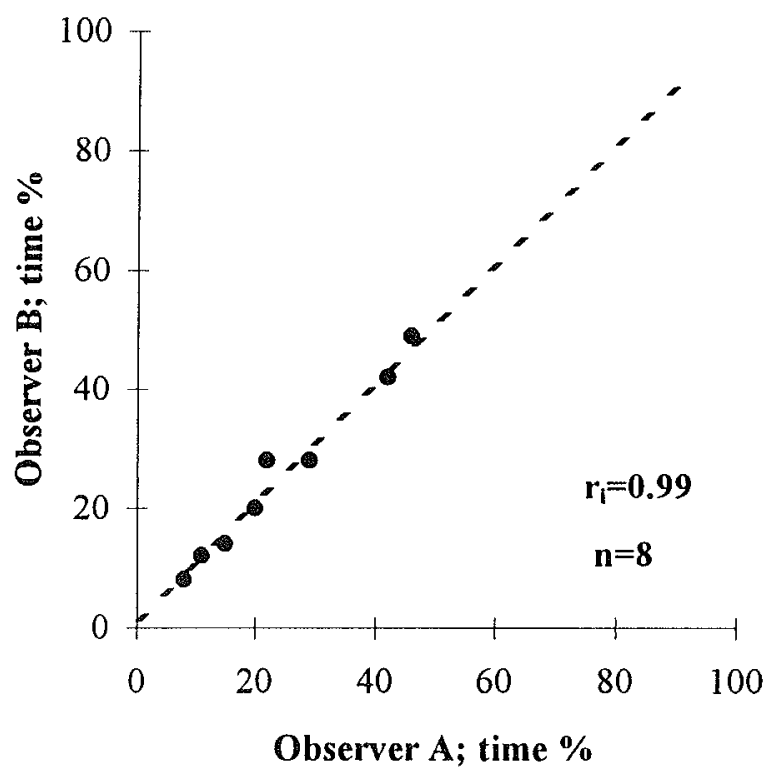

Figure 2. Plot of the observed percentage of time spent with the hands not fixed between shoulder and knuckle level registered by observer $A$ $(x$-axis) and observer $B(y$-axis) for eight subjects $(n)$ during full-day registrations. The line of identity (dotted line) and the intraclass correlation coefficient $\left(r_{i}\right)$ are also presented.
For each of the five postures registered on one test occasion, the total time, as the percentage of the workshift, was calculated for both observers. The distribution of the durations in the study group was described by the mean, the median, and the range. For each posture, the registrations made by observer $\mathrm{A}$ were compared with corresponding registrations made by observer $\mathrm{B}$, and intraclass correlation coefficients were calculated using a two-way analysis of variance (18). These calculations were made for full-day registrations, for the first hour of the workshift, and for the last hour of the workshift. The intraclass correlation coefficients between the registrations made by the two observers during the first and last hour of the workshift were compared in order to determine whether the long observation period influenced the interobserver reliability negatively (ie, if the correlation declined when the observers could be expected to be tired).

\section{Results}

The mean registration time was 356 (range 306-404) $\min$. The mean time and the range of time spent in each of the five postures registered by observer $\mathrm{A}$ and $\mathrm{B}$ were similar (table 1). The intraclass correlation coefficients between the durations registered by the two observers were high for each of the five postures and ranged from 0.99 to 1.00 for full-day registrations (figure 2, table 1).

The registrations made by the two observers during the last hour of the workshift correlated at least as well as the registrations made during the first hour of the shift (table 1).

The observations made by the untrained observer were very similar to those made by the trained observer (A). The percentage of time registered in each of the five postures was identical between the untrained and trained observer for all five postures: "above shoulder level" $0 \%$, "fixed between shoulder and knuckle level" $3 \%$, "not fixed between shoulder and knuckle level" $43 \%$, "below knuckle level" 9\%, and "sitting" $45 \%$.

Table 1. Mean and median of the percentage of time (a workday) spent in each of five work postures, as measured simultaneously by two observers for eight subjects. The intraclass correlation coefficients between the durations registered by the two observers for full-day registrations, the first hour, and last hour of the workshift are also presented.

\begin{tabular}{|c|c|c|c|c|c|c|c|c|c|}
\hline \multirow[t]{3}{*}{ Work posture } & \multicolumn{6}{|c|}{ Percentage of time } & \multicolumn{3}{|c|}{ Intraclass correlation coefficients } \\
\hline & \multicolumn{3}{|c|}{ Observer A } & \multicolumn{3}{|c|}{ Observer B } & \multirow{2}{*}{$\begin{array}{l}\text { Total } \\
\text { shift }\end{array}$} & \multirow{2}{*}{$\begin{array}{l}\text { First } \\
\text { hour }\end{array}$} & \multirow{2}{*}{$\begin{array}{l}\text { Last } \\
\text { hour }\end{array}$} \\
\hline & Mean & Median & Range & Mean & Median & Range & & & \\
\hline Sitting & 14 & 11 & $0-29$ & 13 & 10 & $0-29$ & 1.00 & 0.97 & 1.00 \\
\hline Standing, hands above shoulder & 12 & 6 & $0-44$ & 14 & 6 & $0-44$ & 1.00 & 0.85 & 1.00 \\
\hline Standing, hands fixed between shoulder \& knuckle & 34 & 28 & $7-70$ & 33 & 30 & $7-71$ & 0.99 & 0.96 & 0.99 \\
\hline Standing, hands not fixed between shoulder \& knuckle & 24 & 21 & $8-46$ & 25 & 24 & $8-49$ & 0,99 & 0.88 & 1.00 \\
\hline Standing, hands below knucke & 16 & 6 & $1-77$ & 16 & 6 & $1-78$ & 1.00 & 0.99 & 1.00 \\
\hline
\end{tabular}




\section{Intermethod reliability}

Two of the work postures, work with the hands above shoulder level (posture 1) and work with the hands below knuckle level (posture 4), were compared with technical measurements made by an arm position analyzer and a trunk flexion analyzer. The purpose was to evaluate whether there was a linear relationship between the time spent with elevated arms and hands above shoulder level and between the time spent with the trunk flexed and the hands below knuckle level. If so, the observed time with the hands above shoulder level could be used as a proxy for elevated arms, and the observed time spent with the hands below knuckle level could be used as a proxy for a flexed trunk.

\section{Subjects and methods}

The study group consisted of 72 blue-collar workers, 58 men and 14 women from nine occupations. The subjects were selected from occupations with a wide range of times spent in standing or walking positions. Thus ceiling builders $(\mathrm{N}=14)$, sprinkler workers $(\mathrm{N}=6)$, carpet layers $(\mathrm{N}=8)$, railway track layers $(\mathrm{N}=8)$, concrete workers reinforcing floors $(\mathrm{N}=4)$, chocolate assemblyline workers $(\mathrm{N}=8)$, car assembly-line workers $(\mathrm{N}=8)$, packers $(\mathrm{N}=8)$, and machine-tool operators $(\mathrm{N}=8)$ were selected to represent these different work postures. The mean age of the study group was 35 (range 18-63) years, the mean body weight was 74 (range $51-98$ ) kg, and the mean body height was 176 (range: 151-193) $\mathrm{cm}$.

\section{Reference measurements}

The observed time spent standing with the hands above shoulder level was compared with data from an arm position analyzer (Abduflex, Sweden). The Abduflex continuously registers the angle between the upper arm and the vertical in seven 15-degree intervals: $0-15^{\circ}$, $15-30^{\circ}, 30-45^{\circ}, 45-60^{\circ}, 60-75^{\circ}, 75-90^{\circ}$, and $>90^{\circ}(19)$. The accuracy of the measurements obtained by the arm position analyzer was tested in relation to a computer-based three-dimensional video analyzing system (Mac Reflex, Qualisys, Sweden) and considered valid for the present purpose (Ericson et al, unpublished material). The sensors (one for each arm) of the Abduflex were attached to the upper arm below the insertion of the deltoid muscle, and the box for data collection was placed on a waist band (figure 3). At the end of the registrations, data were transmitted to and analyzed on a personal computer with a specially developed upperarm position analyzing program. The sampling frequency for data transmitted to the personal computer was $1 \mathrm{~Hz}$.

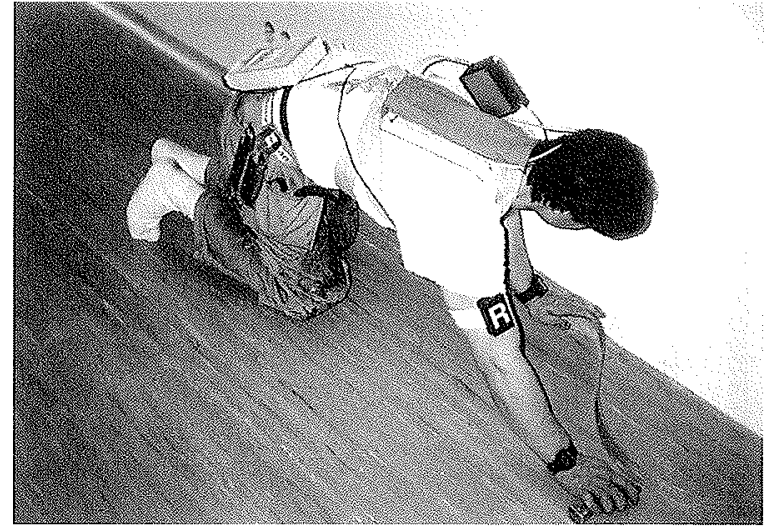

Figure 3. A carpet layer working with an arm position analyzer and a trunk flexion analyzer attached to his body.

The observed time spent standing with the hands below knuckle level was compared with data obtained from a trunk flexion analyzer (20). The trunk flexion analyzer continuously registered the sagittal angle between the trunk and the reference trunk position of standing upright with the arms hanging by the sides; it was a further development of an instrument used elsewhere (21). In the present study the sampling frequency was $0.5 \mathrm{~Hz}$. The sensor and the box for data collection was attached to the back at the Th5-Th10 level with a specially designed rucksack (figure 3 ). At the end of the registration, data were transmitted to and analyzed on a personal computer with a specially developed trunk flexion analyzing program.

The registrations lasted one workshift per worker but had to be interrupted earlier in some cases because of technical errors. Five experienced ergonomists made the observations. One ergonomist followed each subject during the whole workshift.

\section{Data analysis}

For the observed postures the total time was calculated as the percentage of the workshift.

The arm position and trunk flexion analyzers measured continuously. The data recorded during sitting work and breaks were excluded during the analysis to allow comparison with the observations. The total percentage of time spent standing with either of the upper arms elevated $>30^{\circ},>45^{\circ},>60^{\circ},>75^{\circ}$, and $>90^{\circ}$, measured by the Abduflex, was then calculated. The total percentage of time spent standing with the trunk flexed $>20^{\circ},>40^{\circ},>60^{\circ}$, and $>80^{\circ}$, measured by the trunk flexion analyzer, was also calculated.

The relation between the observations and the reference measurements was assessed by linear regression analysis and Pearsons' product moment correlation coefficient (22). In the linear regression analysis the observations were treated as the independent variable and the technical measurements as the dependent variable. 


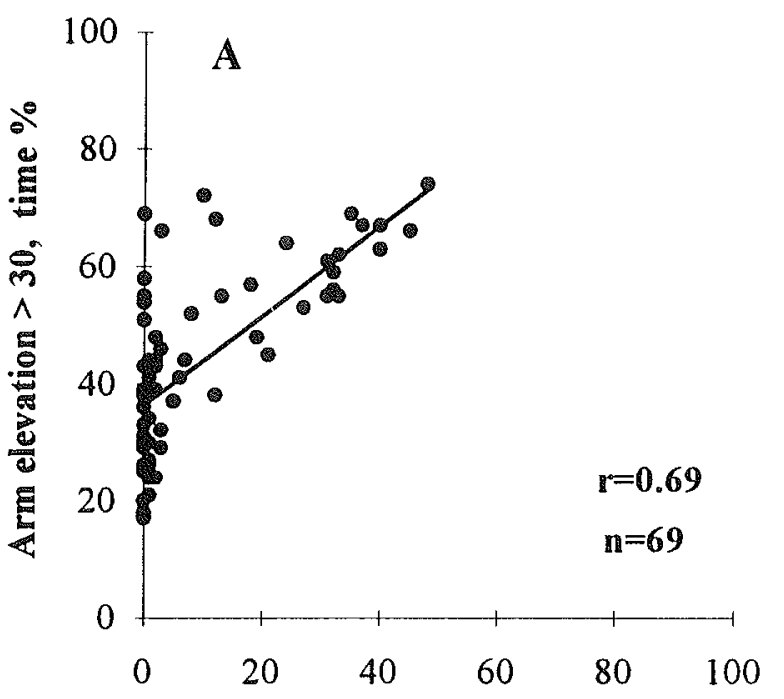

Hands above shoulder, time \%

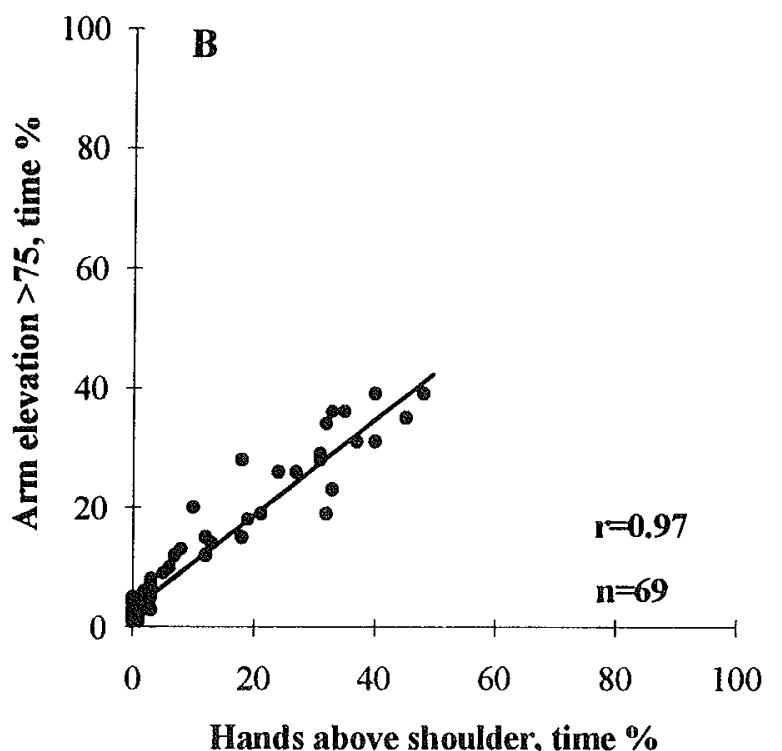

Figure 4. Plots of the observed percentage of time spent with the hands above shoulder level versus the measured percentage of time spent with the upper arms elevated more than $30^{\circ}(\mathrm{A})$ and more than $75^{\circ}(\mathrm{B})$ for 69 subjects $(n)$ - linear regression lines with the observed time as the independent variable and arm elevation as the dependent variable. The product moment correlation coefficients ( $r$ ) are also presented.
Results

\section{Registered and missing values}

The mean registration time was 374 (range 196-500) $\min$. For one subject the whole-day observation registrations failed due to technical reasons. For two subjects the arm position registrations failed, and for nine the trunk flexion registrations failed, also due to technical reasons. Thus the relationship between the observed time spent standing with the hands above shoulder level and standing with the upper arm elevated $>30^{\circ},>45^{\circ}$, and so forth was analyzed for 69 subjects. The relationship between the observed time spent standing with the hands below knuckle level and time registered by the trunk flexion analyzer for standing with the trunk flexed $>20^{\circ}$, $>40^{\circ}$, and so forth was analyzed for 62 subjects.

\section{Relationship between the observations and the results of the arm position analyzer}

The mean time spent with the hands above shoulder level was $10 \%$ of a workshift and the median was 2 (range 0 $48) \%$, as registered with the observation technique. Twenty-three subjects were registered as not exposed $(0 \%)$ to work with hands above shoulder level. Nevertheless, they worked from 17 to $69 \%$ of the time with the upper arms elevated $>30^{\circ}$ (figure $4 \mathrm{~A}$ ). The correlation coefficient ( $r$ ) between the observed duration of the hands above shoulder level and the measured duration of elevated upper arms defined as $>30^{\circ}$ was 0.69 , the $y$-axis intercept of the regression line was $37 \%$, and the slope 0.76 (figure $4 \mathrm{~A}$, table 2 ). Thus a linear regression line did not fit the data in all aspects. The correlation coefficient between the observed duration of hands above shoulder level and the measured duration of elevated upper arms defined as $>75^{\circ}$ was 0.97 , the $y$-axis intercept of the regression line was $3 \%$, and the slope 0.80 (figure $4 \mathrm{~B}$, table 2 ). Thus the time spent with the upper arms elevated $>75^{\circ}$ could be predicted by observing the hands above shoulder level.

When the subjects $(\mathrm{N}=18)$ selected to represent work with the hands above shoulder level were excluded

Table 2. Mean and median of the percentage of time (a workday) spent with the upper arms elevated $>30^{\circ},>45^{\circ},>60^{\circ},>75^{\circ}$, and $>90^{\circ}$, as registered by an arm position analyzer for 69 subjects. The product moment correlation coefficients between these times and the observed time spent with the hands above shoulder height are presented. The intercepts $\left(\beta_{0}\right)$ and slopes $\left(\beta_{1}\right)$, with standard errors, of the linear regression lines with the observed time spent with the hands above shoulder height as the independent variable and the different upper arm elevation angles as the dependent variables are also presented.

\begin{tabular}{|c|c|c|c|c|c|c|c|c|}
\hline \multirow[t]{2}{*}{ Upper arm angles } & \multicolumn{3}{|c|}{ Percentage of time } & \multirow{2}{*}{$\begin{array}{l}\text { Correlation } \\
\text { coefficient }\end{array}$} & \multicolumn{2}{|c|}{ Intercept } & \multicolumn{2}{|c|}{ Slope } \\
\hline & Mean & Median & Range & & $\beta_{0}$ & SE & $\beta_{1}$ & SE \\
\hline $\begin{array}{l}\left.>30^{\circ} \text { (\% time }\right) \\
\left.>45^{\circ} \text { (\% time }\right) \\
\left.>60^{\circ} \text { (\% time }\right) \\
\left.>75^{\circ} \text { (\% time }\right) \\
>90^{\circ}(\% \text { time })\end{array}$ & $\begin{array}{r}44 \\
24 \\
16 \\
11 \\
8\end{array}$ & $\begin{array}{r}43 \\
19 \\
9 \\
5 \\
2\end{array}$ & $\begin{array}{r}17-74 \\
8-52 \\
3-43 \\
1-39 \\
0-36\end{array}$ & $\begin{array}{l}0.69 \\
0.88 \\
0.95 \\
0.97 \\
0.95\end{array}$ & $\begin{array}{r}37 \\
16 \\
7 \\
3 \\
1\end{array}$ & $\begin{array}{l}1.64 \\
0.98 \\
0.60 \\
0.45 \\
0.48\end{array}$ & $\begin{array}{l}0.76 \\
0.86 \\
0.86 \\
0.80 \\
0.69\end{array}$ & $\begin{array}{l}0.10 \\
0.06 \\
0.04 \\
0.03 \\
0.03\end{array}$ \\
\hline
\end{tabular}


from the analysis, the range of the duration of hands above shoulder level was narrowed to $0-12 \%$ for the remaining 51 subjects. The correlation coefficients between the duration of hands above shoulder level and the duration of elevated upper arms, defined as $>30^{\circ},>45^{\circ}$, and so forth, deteriorated but remained highest for pronounced upper arm elevation angles, defined as $>75^{\circ}$ (r $=0.91$ ).

\section{Relationship between the observations and the result of the trunk flexion analyzer}

The mean time spent with the hands below knuckle level was $14 \%$ of a workshift, and the median was 5 (range $0-78) \%$, as registered with the observation technique. Twenty-three subjects worked less than $3 \%$ of the time with their hands below knuckle level, but they spent between 7 and $41 \%$ of the time with the trunk flexed $>20^{\circ}$ according to data from the trunk flexion analyzer (figure $5 \mathrm{~A}$ ). The correlation coefficient between the observed duration of hands below knuckle level and the measured duration of trunk flexion, defined as angles $>20^{\circ}$, was 0.90 , the $y$-axis intercept of the regression line was $16 \%$, and the slope 0.85 (figure $5 \mathrm{~A}$, table 3 ). Thus a linear regression line did not fit the data in all aspects. The correlation coefficient between the observed duration of hands below knuckle level and measured duration of trunk flexion, defined as angles $>40^{\circ}$, was 0.98 , the $y$-axis intercept of the regression line was $3 \%$, and the slope 0.91 (figure $5 \mathrm{~B}$, table 3 ). Thus the time spent with the trunk flexed $>40^{\circ}$ could be predicted by observing the hands below knuckle level.

When the subjects $(N=18)$ selected to represent work below knuckle level were excluded from the analysis, the range of durations of work with hands below knuckle level was narrowed to $0-12 \%$ for in the remaining subjects. The correlation coefficients between the observed duration of hands below knuckle level and the measured duration of trunk flexion, defined as $>20^{\circ}$, $>40^{\circ}$, and so forth, deteriorated but remained highest for pronounced trunk flexion angles defined as $>40^{\circ}$ ( $\mathrm{r}=$ $0.81)$.

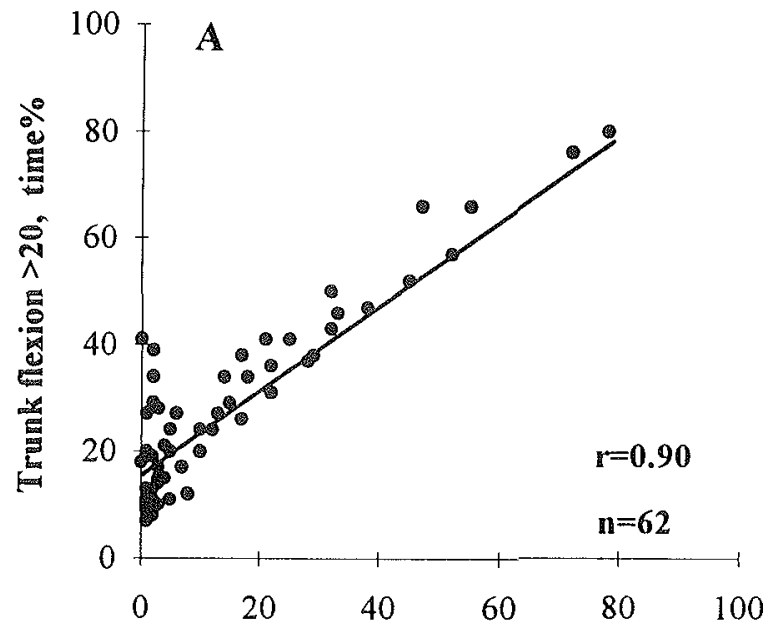

Hands below knuckle, time \%

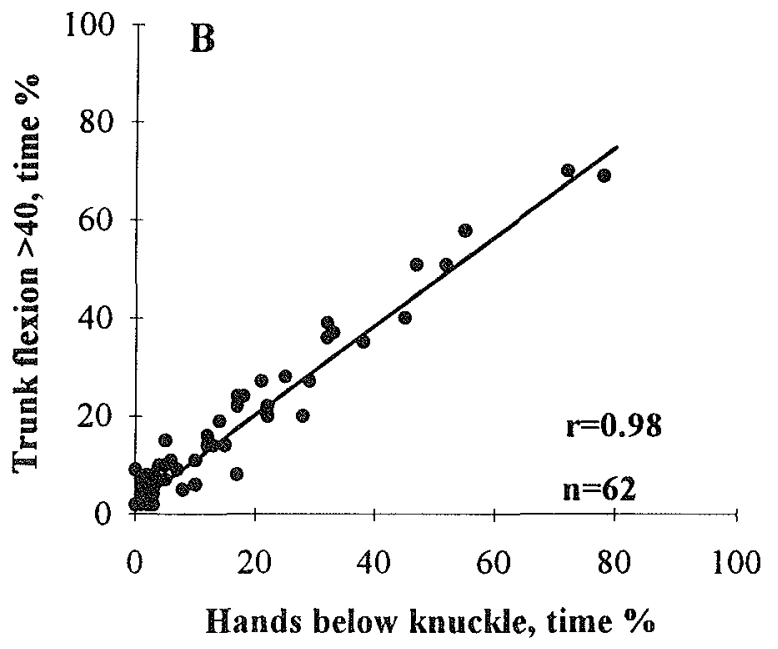

Figure 5. Plots of the observed percentage of time spent with the hands below knuckle level versus the measured percentage of time spent with the trunk flexed forward $>20^{\circ}(\mathrm{A})$ and $>40^{\circ}(\mathrm{B})$ for 62 subjects $(\mathrm{n})$ linear regression lines with the observed time as the independent variable and trunk flexion as the dependent variable. The product moment correlation coefficients ( $r$ ) are also presented.

Table 3. Mean and median of the percentage of time (a workday) spent with the trunk flexed forward $>20^{\circ},>40^{\circ},>60^{\circ}$, and $>80^{\circ}$, as registered by a trunk flexion analyzer for 62 subjects. The product moment correlation coefficients between these times and the observed time spent with the hands below knuckle height are presented. The intercepts $\left(\beta_{0}\right)$ and slopes $\left(\beta_{1}\right)$, with standard errors, of the linear regression lines with the observed time spent with the hands above shoulder height as the independent variable and the different upper arm elevation angles as the dependent variables are also presented.

\begin{tabular}{|c|c|c|c|c|c|c|c|c|}
\hline \multirow[t]{2}{*}{ Trunk flexion angles } & \multicolumn{3}{|c|}{ Percentage of time } & \multirow{2}{*}{$\begin{array}{l}\text { Correlation } \\
\text { coefficient }\end{array}$} & \multicolumn{2}{|c|}{ Intercept } & \multicolumn{2}{|c|}{ Slope } \\
\hline & Mean & Median & Range & & $\beta_{0}$ & SE & $\beta_{\uparrow}$ & SE \\
\hline $\begin{array}{l}>20^{\circ} \\
>40^{\circ} \\
>60^{\circ} \\
>80^{\circ}\end{array}$ & $\begin{array}{r}28 \\
16 \\
11 \\
7\end{array}$ & $\begin{array}{r}26 \\
8 \\
4 \\
1\end{array}$ & $\begin{array}{l}7-80 \\
2-70 \\
0-65 \\
0-44\end{array}$ & $\begin{array}{l}0.90 \\
0.98 \\
0.96 \\
0.89\end{array}$ & $\begin{array}{r}16 \\
3 \\
0 \\
-1\end{array}$ & $\begin{array}{l}1.28 \\
0.66 \\
0.74 \\
0.85\end{array}$ & $\begin{array}{l}0.85 \\
0.91 \\
0.78 \\
0.52\end{array}$ & $\begin{array}{l}0.06 \\
0.03 \\
0.03 \\
0.04\end{array}$ \\
\hline
\end{tabular}




\section{Discussion}

Our observation method had a high interobserver reliability even when an untrained ergonomist made the observations. The reliability was at least as good during the last hour of the workshift as during the first, indicating that it can be used during whole days.

There was a strong linear relationship between the observed duration of hands above shoulder level and the measured duration of pronounced arm elevation $\left(>75^{\circ}\right)$ and a weaker relationship for angles above $30^{\circ}$. In epidemiologic studies work above shoulder level and elevated (abducted or flexed) arms are both suggested as risk factors for neck and shoulder disorders (4). Work with the hands above shoulder level always implies outward rotation of the arm, whereas moderately elevated arms does not. It is still unknown whether elevation and outward rotation of the arm causes higher risk than only elevation. In a study on postural risk factors for rotator cuff tendinitis, Fine et al (23) did not find any relation between arm elevation and rotator cuff tendinitis, but there was a relationship between outward rotation and rotator cuff tendinitis. On the other hand, in a biomechanical study, Sigholm et al (1) showed that the degree of upper arm elevation was the most important parameter influencing shoulder muscle load. We have not found any quantitative data on the amplitude or the duration of arm elevation or outward rotation necessary to cause the increased risk.

There was a strong linear relationship between the observed duration of work with hands below knuckle level and the measured duration of pronounced trunk flexion angles $\left(>40^{\circ}\right)$, and the relationship was weaker for angles above $20^{\circ}$. Punnet et al (24), in a study of automobile assembly workers, described a strong increasing trend in risk both with its intensity of exposure and with the duration. Pronounced trunk flexion angles $\left(>45^{\circ}\right)$ caused a higher risk than mild trunk flexion $\left(20^{\circ}-45^{\circ}\right.$ ), and a long duration (more than $10 \%$ of the time) of trunk flexion caused a higher risk than a short duration $(0-10 \%)$. However, there are too few quantitative studies on the magnitude and duration of trunk flexion to draw any conclusions about a possible exposureresponse relationship.

\section{Interobserver reliability}

The reproducibility (ie, the interobserver reliability) determined in our study was high. Other observation methods have been tested for interobserver reliability (12, $14-16,25,26)$, but no comparisons can be made since the number of postures observed simultanously and the registration periods differed. In the method designed by Foreman et al (25) the number of events was 43 , and in our study it was only 5 . In the interobserver reliability study made by Keyserling (14) the registration period covered $68 \mathrm{~s}$, and in our study the median registration period was $364 \mathrm{~min}$.

The high correlation found by us may be due to the simplicity of the definitions of postures. Only five mutually exclusive postures were observed, and the observer could concentrate on two parts of the body, the hands of the worker. Therefore it was possible to make fairly correct observations during a whole workshift. The observers found the postures "sitting," "hands above shoulder level," and "hands below knuckle level" easy to classify. In some worktasks it was difficult to decide whether the hands were fixed or not, when the work was performed between the shoulder and knuckle level, especially at the beginning of the recording period (table 1). The difficulty in discriminating between these two postures arises in tasks where one hand is used most of the time and the other hand is used for short periods. In our study these tasks were uncommon and brief, and this circumstance explains the high correlations. In another study group including workers with tasks in which only one hand was used, the reproducibility of these two postures would presumably be lower.

A bias in the registrations could have been introduced if the movement frequency between the defined posture boundaries had been high. In our study such movements were rare.

When the untrained ergonomist made the observations, the observed subject's work tempo was low. The worker sat $45 \%$ of the time waiting for work pieces to be delivered. This situation may partly explain the high correlation.

In the analysis it appeared that the agreement between observers was higher during the last hour of the observation than during the first. Both the observer and the subject acted differently during the first hour. The subject could not act naturally, and there is often some talking between the subject and the observer to create a relaxed atmosphere. After about $1 \mathrm{~h}$ at the workplace the observer has a good idea of the work situation and the worktasks performed, and the reliability of the observations increases. However, a positive atmosphere and a highly motivated observer is required to maintain a high level of attention during several hours of observations.

\section{Intermethod reliability}

The correlation between the observed time with the hands below knuckle level and the measured time with the trunk pronouncedly flexed $\left(>40^{\circ}\right)$ was high $(0.98)$. In one study made by Baty et al (27), a trunk flexed position was defined to be angles more than $15^{\circ}$ relative to the vertical, and Burdorf et al (28) defined a trunk flexed position as angles of $>20^{\circ}$. In these studies the correlation coefficients were lower $(0.63$ and 0.57$)$ between the 
observations and measurements than in our study. One explanation may be that it is easier to distinguish between the hands being placed above or below an imaginary line at the knuckle level than to estimate the inclination angle of the trunk relative to the vertical, at least when the trunk inclination angle is small, the view angle is poor, and the observations are made in real time. Another explanation could be that different trunk inclinometers were used as reference measurements in the three studies. In Baty et al's study the range of the duration of trunk flexion was narrower than in our study, and this difference can be a third explanation for the lower correlation coefficients found in their study.

The high correlations found in our study could partly be due to the selection of the study group. However, even when the subjects selected to represent jobs performed below the knuckle level were excluded from the analysis, the correlation between the duration of hands below knuckle level and the duration of pronounced forward flexed positions of $>40^{\circ}$ was high. The decrease in correlation, from 0.98 to 0.81 , can be explained by the decrease in the range of exposures among the subjects analyzed. It may be uncommon to work with the trunk flexed forward as much as $40^{\circ}$ without having the worktask placed below knuckle level.

Several subjects worked with the trunk moderately flexed $\left(>20^{\circ}\right)$ without the observer making any registrations of work below knuckle level (figure $5 \mathrm{~A}$ ). The intercept of the regression line for the observed time with the hands below knuckle level and the measured time with trunk flexion $>20^{\circ}$ was $16 \%$ of the time (table 3 ). It may be common to have the trunk moderately flexed forward also when working with the hands above knuckle level (eg, when reaching for objects in front of the body). Thus, if the aim is to measure pronounced forward bent positions $\left(>40^{\circ}\right.$ ), this observation method may be good. If the objective is also to measure moderate forward bent positions $\left(>20^{\circ}\right)$, several truly exposed subjects may be classified as unexposed. In an epidemiologic study this type of error will dilute a potential increased risk towards unity.

The placement of the hands above shoulder level was assumed to mirror work with elevated arms. Theoretically, the upper arm can be elevated up to $90^{\circ}$ relative to the vertical without the hand being positioned above the shoulder, for instance, when working on a high table. In our study the correlation was high between hands above shoulder level and pronounced upper arm elevation (more than $75^{\circ}$ ) (table 2, figure $4 \mathrm{~B}$ ). Even when the subjects selected to represent jobs performed with the hands above shoulder level were excluded from the analysis the correlation remained high. It may be uncommon to work with the upper arms elevated as much as $75^{\circ}$ or more without having the worktask above shoulder level. Several subjects worked with moderately $\left(>30^{\circ}\right)$ ele- vated arms without the observer making any registrations of hands above shoulder level (table 2, figure 4A). It may be common to work with moderately elevated arms also when the worktask is placed below shoulder level. Thus, if the aim is to measure pronounced upper arm elevation, the present observation technique may be a method to recommend. If the goal is also to measure moderate arm elevation angles, several truly exposed subjects will be classified as unexposed.

In traditional observation methods the position of the arm is usually defined by estimating abduction and flexion angles of the upper arm $(10,12,14,26,29,30)$. The reliability of such methods may be acceptable at least when the analysis is made from video recordings which allow playback of the film. When upper arm flexion and abduction angles were measured by the VIRA (video film technique for registration and analysis of work posture and movement) method, the interobserver reliability was high for upper arm angles over $30^{\circ}$, but poor for angles below $30^{\circ}$ (12). In a study made by Keyserling (14) continuous registrations of the time spent in each of three upper arm elevation angle intervals $\left(0^{\circ}-45^{\circ}, 45^{\circ}-90^{\circ},>90^{\circ}\right)$ were compared with a frameby-frame technique involving a 75 -s video recording. The time spent in each angle interval measured with the two methods corresponded well. However, it is timeconsuming to estimate the arm elevation angles on video recordings for long time periods.

\section{Applicability and drawbacks of the present observation method}

Ideally, the total external moment acting on a specific joint or structure should be registered. Therefore, all external forces, including the weight of separate body parts and corresponding moment arms (in three dimensions) acting on a certain joint or structure should be observed continuously over time. This is impossible to do practically. HARBO is a simple method and only registers five standard postures. It does not include twisted postures since the interobserver reliability for them is poor $(26,27)$. Neither does it discriminate between the right and left hand. Short events like a lift may not be registered at all. The observer must have time to be made aware of a change of posture and hit the corresponding key on the keyboard. Work with moderately elevated upper arms and moderately flexed trunk positions is only partly registered. However, the method is easy to modify, and we can recommend the software we used in the present study.

The measurement and analysis of work postures has two important occupational health applications: (i) obtaining exposure data to use in epidemiologic investigations of posture-related injuries and (ii) obtaining expo- 
sure data to use in ergonomic prevention and intervention programs.

Punnet \& Keyserling (17) discussed the limitations of traditional motion analysis techniques designed to examine one or a few short-cycle jobs in great detail. These techniques are generally time-consuming and costly. For epidemiologic research in particular, data on the sources of variability in exposure among individuals (intraindividual and interindividual) is critical to achieve unbiased and precise exposure assessments. If the intraindividual variability of exposure is high, the data collection time must be long or repeated measurements must be made. If the interindividual variability is high within a job, data must be collected individually. In epidemiologic studies and in ergonomic intervention studies, in which long observation periods are required to get representative exposure data, our method may be preferable. Traditional motion analysis techniques are more detailed and may therefore be preferable in studies of repetitive shortcycled work, where the intraworker variability of exposure is low.

\section{Concluding remarks}

Our observation method is designed to make observations continuously for several hours. The observed number of posture categories are few and mutually exclusive (ie, only one decision has to be made at a time). Registrations are only made when a change occurs. The present method may be a complement to traditional observation methods to be used in epidemiologic studies where the intraworker variability of exposure is high. The method is easy to learn, simple to use, and it can be used in all types of jobs where an observer is allowed. It seems to be reliable and comparatively cheap since there is no extra time needed for data analysis. It seems to reflect work with pronounced arm elevation or pronounced trunk flexion accurately. However, it does not take twisted positions or manual materials handling into consideration.

\section{Acknowledgments}

This study was supported by grants from the Stockholm County Council and the Swedish Work Environment Fund.

We are grateful to Mats Ericson, $\mathrm{PhD}$, for his valuable help with the technical instruments and to Kristina Selin, MSc, and Gunilla Pernold for their highly qualified work in the data collection and for valuable comments on the manuscript. We are also grateful to Max Köster, BSc, and Lars Walter, BSc, for their valuable help with the statistical analyses.

\section{References}

1. Sigholm G, Herberts P, Almström C, Kadefors R. Electromyographic analysis of shoulder muscle load. J Orthop Res 1984; $1: 379-386$

2. Järvholm U, Palmerud G, Styf J, Herberts P, Kadefors R. Intramuscular pressure in the supraspinatus muscle. J Orthop Res 1988:6:230-238.

3. Lind M. Biomechanics of the lumbar spine. In: Nordin M, Frankel VH, editors. Basic biomechanics of the musculoskeletal system. 2nd edition. Philadelphia, London: Lea and Febiger, 1989:183-207.

4. Winkel J, Westgaard R. Occupational and individual risk factors for shoulder-neck complaints, part II: the scientific basis (literature review) for the guide. Int J Ind Ergon 1992;10:85104.

5. Riihimäki H. Low-back pain, its origin and risk indicators. Scand J Work Environ Health 1991;17:81—90.

6. Stock S. Workplace ergonomic factors and the development of musculoskeletal disorders of the neck and upper limbs: a meta-analysis. Am J Ind Med 1991;19:87-107.

7. Winkel J, Mathiassen E. Assessment of physical work load in epidemiologic studies: concepts, issues and operational considerations. Ergonomics 1994;37:979—88.

8. Sommerich C, McGlothlin J, Marras W. Occupational risk factors associated with soft tissue disorders of the shoulder: a review of recent investigations in the literature. Ergonomics 1993;36:697-717.

9. Burdorf A. Exposure assessment of risk factors for disorders of the back in occupational epidemiology. Scand J Work Environ Health 1992;18:1-9.

10. Priel V. A numerical definition of posture. Hum Factors 1974; $16: 576-84$

11. Corlett N, Madeley S, Manenica I. Posture targetting: a technique for recording working postures. Ergonomics 1979;22: $357-66$.

12. Kilbom $\AA$, Persson J, Jonsson B. Risk factors for work-related disorders of the neck and shoulder- with special emphasis on working postures and movements. In: Corlett $\mathrm{N}$, Wilson J, Manenica I, editors. The ergonomics of working postures: proceedings of the First International Occupational Ergonomics Symposium, April 15-17 1985. London and Philadelphia: Taylor \& Francis, 1986:44—53.

13. Kilbom $\AA$. Assessment of physical exposure in relation to work-related musculoskeletal disorders - what information can be obtained from systematic observations? Scand J Work Environ Health 1994;20 special issue:30-45.

14. Keyserling M. Postural analysis of the trunk and shoulders in simulated real time. Ergonomics 1986;29:569-83.

15. Fransson-Hall C, Gloria R, Karlqvist L, Wiktorin C, Winkel J, Kilbom $\AA$, Stockholm MUSIC I study group. A portable ergonomic observation method (PEO) for computerized on-line recording of postures and manual handling. Appl Ergon 1995 26:93-100.

16. Kivi P, Mattila. Analysis and improvement of work postures in the building industry: application of the computerised OWAS method. Appl Ergon 1991;22:43 - 8.

17. Punnet L, Keyserling M. Exposure to ergonomic stressors in the garment industry: application and critique of job-site work analysis methods. Ergonomics 1987;30:1099-116.

18. Armstrong BK, White E, Saracci R. Principles of exposure measurement in epidemiology. 1st edition. Oxford: Oxford University Press, 1992:78 - 114.

19. Ericson MO, Heijdenberg J, Wallin K. Abduflex. Portable 
system for field measurements of arm postures and motions: technical report. Stockholm: Royal Institute of Technology, 1994:31.

20. Ericson MO. Portable inclinometer system for measurement of trunk postures. Stockholm: Royal Institute of Technology, 1994:5.

21. Nordin M, Örtengren R, Andersson GBJ. Measurement of trunk movements during work. Spine 1984;9:465-9.

22. Glantz S, Slinker B. Primer of applied regression and analysis of variance. 1st edition. New York (NY): McGraw-Hill, 1990: $10-39$

23. Fine L, Silverstein B, Armstrong T, Joseph B, Buchholz B. A pilot study of postural characteristics of jobs associated with elevated risk of rotator cuff tendinitis. In: Corlett N, Wilson J, Manenica I, editors. The ergonomics of working postures: proceedings of the First International Occupational Ergonomics Symposium, April 15-17 1985. London and Philadelphia: Taylor \& Francis 1986:39-43.

24. Punnet L, Fine L, Keyserling M, Herrin G, Chaffin D. Back disorders and nonneutral trunk postures of automobile assembly workers. Scand J Work Environ Health 1991;17:337-46.

25. Foreman T, Davies J, Troup J. A posture and activity classification system using a micro computer. Int J Ind Ergon 1988;2: $285-9$.
26. van der Beek A, van Gaalen L, Frings-Dresen M. Working postures and activities of lorry drivers: a reliability study of on-site observation and recording on a pocket computer. Appl Ergon 1992;5:331-6.

27. Baty D, Buckle PW, Stubbs DA. Posture recording by direct observation, questionnaire assessment and instrumentation: a comparison based on a recent field study. In: Corlett N, Wilson J, Manenica I, editors. The ergonomics of working postures: proceedings of the First International Occupational Ergonomics Symposium, April 15-17 1985. London and Philadelphia: Taylor \& Francis 1986:283-91

28. Burdorf A, Derksen J, Naaktgeboren B, van Riel M. Measurement of trunk bending during continuous measurement. Appl Ergon 1992;23:263-7.

29. McAtamney L, Corlett N. Survey method for the investigation of work related upper limb disorders. In: Quéinnec Y, Daniellou F, editors. Designing for everyone: proceedings of the XI Congress of the International Ergonomics Association. London: Taylor \& Francis, 1991;1:141-3.

30. Corlett and Manenica I. The effects and measurement of working postures. Appl Ergon 1980;11:7-16

Received for publication: 14 November 1994. 